\title{
A realidade virtual e seu uso como recurso terapêutico ocupacional: revisão integrativa
}

\author{
Tayane Leoncio Caiana, Dhyego de Lima Nogueira, Ana Carollyne Dantas de Lima
}

Departamento de Terapia Ocupacional, Universidade Federal da Paraíba - UFPB, João Pessoa, PB, Brasil.

\begin{abstract}
Resumo: Introdução: A Realidade Virtual (RV) é definida como a interface entre o usuário e a simulação computadorizada em um determinado ambiente ou atividade, oferecendo interação através de múltiplos canais sensoriais encontrados em videogames ou computadores, propiciando ao indivíduo vivências diversas. É uma prática crescente nas profissões da saúde, dentre as quais a Terapia Ocupacional. Objetivo: Analisar como a Realidade Virtual vem sendo utilizada nos processos terapêuticos ocupacionais, a partir de publicações nacionais, com o uso desta abordagem, nos últimos anos. Método: Trata-se de uma revisão integrativa de literatura, entre 2004 e 2014, com os seguintes descritores: Terapia Ocupacional, Jogos de Vídeo, Terapia de Exposição à Realidade Virtual, Terapia Assistida por Computador e Interface Usuário-Computador, utilizando as bases do Portal CAPES, LILACS, MEDLINE e SciELO, os periódicos da Terapia Ocupacional (Revista de Terapia Ocupacional da USP e Cadernos de Terapia Ocupacional da UFSCar) e o Google Scholar, para a busca livre de capítulos de livros. Resultados: Foram selecionados 15 artigos obedecendo aos critérios de inclusão. Observou-se que a maioria relacionava a Realidade Virtual como um método avaliativo ( $\mathrm{n}=07 ; 46,6 \%$ ), intervindo em desordens neurológicas $(\mathrm{n}=10 ; 66,6 \%)$, utilizado mais frequentemente pelo público adolescente $(\mathrm{n}=07 ; 46,6 \%)$ e o computador foi o equipamento mais utilizado nas intervenções ( $n=10 ; 66,6 \%)$. Conclusão: A RV é uma ferramenta importante na promoção de saúde e em diversos tratamentos; seu uso vem crescendo entre os terapeutas ocupacionais, mas ainda é uma área que precisa ser evidenciada com mais afinco para que sirva como um auxílio para a atualização de técnicas.
\end{abstract}

Palavras-chave: Jogos de Vídeo, Realidade Virtual, Terapia de Exposição à Realidade Virtual, Terapia Ocupacional.

\section{Virtual reality and its use as occupational therapeutic resource: an integrative review}

\begin{abstract}
Introduction: Virtual Reality is defined as the interface between the user and the computer simulation of a given environment or activity, providing interaction through multiple sensory channels found in video games or computers, offering different experiences to the individual. It is a growing practice in health professions, including Occupational Therapy. Objective: To analyze how virtual reality has been used in occupational therapy processes through a search in national publications that have used this approach in recent years. Method: An integrative literature review was conducted at CAPES, LILACS, MEDLINE and SciELO databases, periodicals of Occupational Therapy (Journal of Occupational Therapy - USP and Occupational Therapy Notebooks - UFSCar), and Google Scholar (book chapters) between 2004 and 2014, with the following descriptors: Occupational Therapy, Video Game, Virtual Reality Exposure Therapy, Computer Assisted Therapy, and User-Computer Interface. Results: Fifteen articles were selected in compliance with the inclusion criteria. It was observed that most works addressed Virtual Reality as an evaluative method ( $\mathrm{n}=07 ; 46.6 \%)$, intervening in neurological disorders $(n=10 ; 66.6 \%)$, used more frequently by adolescent audience $(n=07 ; 46.6 \%)$. The computer is the most commonly used equipment in the interventions $(n=10 ; 66.6 \%)$. Conclusion: Virtual Reality is an important tool in promoting health, and it is also used in various treatments. Its use has grown among occupational therapists, but it is still an area that needs to be diligently evidenced, so that it can serve as an aid to update techniques.
\end{abstract}

Keywords: Video Games, Virtual Reality, Virtual Reality Exposure Therapy, Occupational Therapy.

Autor para correspondência: Tayane Leoncio Caiana, Departamento de Terapia Ocupacional, Universidade Federal da Paraíba, Campus I, CEP 58059-900, João Pessoa, PB, Brasil, e-mail: tayanne.v@hotmail.com

Recebido em Fev. 27, 2015; $1^{\text {a }}$ Revisão em Ago. 13, 2015; 2ª Revisão em Nov. 17, 2015; Aceito em Dez. 3, 2015. 


\section{Introdução}

$\mathrm{Na}$ atualidade, através do constante crescimento e desenvolvimento das tecnologias, sobretudo das computacionais, o ser humano pode vivenciar situações sem sua exposição direta, tendo a oportunidade de desempenhar atividades reais em ambientes virtuais, o que podemos conceituar como Realidade Virtual (RV) (NASCIMENTO; CARVALHO; COSTA, 2008). Essas tecnologias também auxiliam as práticas voltadas para diversas áreas, incluindo-se as ciências da saúde, dentro dos processos interventivos, no apoio diagnóstico, em processos terapêuticos e no gerenciamento e educação em saúde (NUNES et al., 2011).

No cuidar em saúde, é importante conhecer e vivenciar açóes humanizadas, promovendo o acolhimento e a utilização de instrumentos e ambientes confortáveis. Essas açôes se caracterizam por Tecnologias e podem ser divididas em: 1) Leve: consiste nas relações estabelecidas; 2) Leve-dura: considerada como os saberes já estruturados, protocolados e bem organizados, mas que, em sua interação com o usuário, habita uma tensão entre o pensamento estruturado e a leveza exigida pelo usuário; 3) Dura: utilização de recursos materiais em saúde, tais como: máquinas de raios-X, instrumento de exames laboratoriais, dentre outros (MERHY, 1998; FEUERWERKER, 2014).

No contexto das tecnologias leve-duras e duras, a Realidade Virtual aborda uma interface entre o usuário e a simulação computadorizada em tempo real de um determinado ambiente, cenário ou atividade, oferecendo interação através de múltiplos canais sensoriais (visuais, auditivos, labirínticos, proprioceptivos e táteis), a partir do uso de vídeo games ou computadores, como recurso (ADAMOVICH et al., 2009).

O caráter lúdico dos jogos influencia em um maior engajamento na atividade, apresentando indícios de que os pacientes que utilizam essa abordagem nos processos terapêuticos demonstram melhora mais rápida, estimulando a atividade cerebral do paciente, aumentando suas capacidades ou prevenindo novas intercorrências (MATOS; GOMES; SASAKI, 2010). Além de favorecer a melhora no desempenho físico, os jogos também apresentam um espaço de desenvolvimento das funçôes cognitivas básicas, por meio da estimulação destas, tais como: atenção, concentração, memória, planejamento e resolução de problemas, podendo influenciar na forma como desempenhamos as atividades no dia a dia (COSTA; CARVALHO, 2005).
Dentre as áreas que utilizam essa abordagem voltada para a prevenção, promoção de saúde e reabilitação, está inclusa a Terapia Ocupacional, que, segundo a WFOT - World Federation of Occupational Therapists (WORLD..., 2012), pode ser descrita como:

[...] uma profissão de saúde centrada no cliente, interessada com a promoção da saúde e bem-estar através da ocupação. $\mathrm{O}$ principal objetivo da Terapia Ocupacional é capacitar as pessoas a participarem nas atividades da vida diária. Os terapeutas ocupacionais alcançam este resultado trabalhando com pessoas e comunidades para melhorar as suas capacidades de exercer as ocupaçóes que querem, precisam, ou se espera que façam, ou modificando a ocupação ou o ambiente para melhor apoiar o seu engajamento ocupacional (tradução nossa).

Ao observar algumas evidências na literatura de benefícios ocasionados pelo uso da RV na área da saúde e no desempenho ocupacional (ALBANI et al., 2002; LIMA; MARINO; PALHARES, 2006; DE GRANDE; GALVÃO; GONDIM, 2011) e o número significativo de publicações nesta área nos últimos anos, justifica-se tratar esse tema a fim de contribuir para o desenvolvimento e a difusão dessa abordagem como recurso terapêutico ocupacional no Brasil.

Assim, esta pesquisa tem como objetivo analisar como a RV vem sendo utilizada nos processos terapêuticos ocupacionais, a partir de publicaçôes nacionais com o uso desta abordagem, nos últimos anos, através de uma revisão integrativa de literatura.

\section{Realidade virtual: conceitos e dispositivos mais utilizados}

A RV tem, como conceito, o uso de tecnologias e interfaces com o usuário para criar o efeito de ambientes virtuais, que incluem objetos interativos com uma forte sensaçáo de presença tridimensional, abordando gráficos que permitem a interação do usuário com o ambiente tecnológico, tendo como objetivo recriar ao máximo a sensação de um ambiente real (LESTON, 1996 apud NETTO; MACHADO; OLIVEIRA, 2002).

Segundo Corrêa e Nunes (2009), a RV pode ser considerada como a junção de três fatores: Interação, o ambiente reage de acordo com a interaçáo do usuário; Envolvimento, o grau de engajamento do usuário em uma aplicaçáo, e Imersão, a sensação de estar dentro de um ambiente virtual. 
A RV surgiu no Brasil na década de 1990, sendo impulsionada pelo avanço tecnológico e pela exposição de pesquisadores a novas tecnologias e iniciativas individuais, integrando áreas multidisciplinares que envolviam computação gráfica, sistemas distribuídos, computação de alto desempenho, sistemas de tempo real, interaçáo humano-computador, como, também, temáticas educacionais e de saúde em geral (KIRNER, 2008).

No que tange à realidade virtual na área da saúde, o maior foco está voltado aos diferentes Consoles (nome dado ao recurso, microcomputador, no qual está armazenado o sistema de jogo), que propiciam ao paciente interação direta com o jogo específico escolhido (REIS, 2005).

Também podemos observar que o uso de computadores e tablets está ligado à $\mathrm{RV}$, tais como softwares e aplicativos criados por especialistas, para diversos tipos de tratamentos, como é visto na pesquisa de Nascimento, Carvalho e Costa (2008), que apresentaram o uso deste recurso como meio para a reabilitaçáo cognitiva com um paciente que tem esquizofrenia, e Mendes et al. (2013), que utilizaram a RV com o objetivo de minimizar o desconforto causado pelos procedimentos terapêuticos do câncer de mama.

Com base na literatura, atualmente, os dispositivos mais frequentemente utilizados são os que apresentam projeçáo e sensores de movimento, os quais podemos observar na Tabela 1.

\section{Terapia ocupacional e realidade virtual}

De acordo com a Associação Americana de Terapia Ocupacional, da sigla em inglês - AOTA (AMERICAN..., 2008), a Terapia Ocupacional atua na promoção de saúde através do envolvimento na ocupação e seus aspectos de intervenção dividem-se em: Áreas de Ocupação, Fatores do Cliente, Habilidades de Desempenho, Padróes de Desempenho, Demandas da Atividade e Contextos e Ambientes.

Os contextos comportam os elementos que exercem influência no desempenho de funções ou desempenho ocupacional, definidos pelo domínio e processo da prática da Terapia Ocupacional, e são categorizados em cultural, pessoal, temporal e virtual. Importante na compreensão do uso da RV para Terapia Ocupacional, o contexto virtual é descrito como a interação por simulação, que pode ocorrer em tempo real ou em tempo aproximado, podendo ser feito sem o contato físico direto (AMERICAN..., 2014, tradução nossa).

No contexto da Terapia Ocupacional, os jogos eletrônicos visam à manutenção da saúde e qualidade de vida, e são vistos como meios que desenvolvem aptidóes físicas, mentais e psicoemocionais, além de contribuir na funçáo motora e cognitiva de indivíduos com ou sem alguma necessidade especial (OLIVEIRA; SILVA; ZAPAROLI, 2011).

Tabela 1. Descrição dos Dispositivos mais utilizados em RV.

\begin{tabular}{|c|c|c|}
\hline Nintendo Wii ${ }^{\circledR}$ & $\begin{array}{l}\text { O Nintendo } W_{i i^{\circledR}} \text {, lançado em } 2006 \text { nos EUA, é o videogame de custo } \\
\text { mais acessível. Na interação jogo-usuário, capta os movimentos pelo } \\
\text { sensor infravermelho acoplado ao controle, refletindo os movimentos do } \\
\text { usuário na TV de forma imediata. }\end{array}$ & $\begin{array}{l}\text { Perrani } \\
\text { e Bressan } \\
(2007)\end{array}$ \\
\hline $\begin{array}{l}\text { Playstation } \\
\text { Move }^{\circledR}\end{array}$ & $\begin{array}{l}\text { O Move é formado pelo controle PlayStation Move } \text { Motion }^{\circledR} \text { e pela câmera } \\
\text { PlayStation Eye }{ }^{\circledR} \text {. Apresenta precisão e noção do posicionamento do } \\
\text { jogador dentro de um espaço } 3 \mathrm{D} \text {, tal como a possibilidade de rastreamento } \\
\text { dos movimentos da cabeça. }\end{array}$ & Sony $^{\mathcal{O}}(2011)$ \\
\hline XBOX Kinect $^{\circledR}$ & $\begin{array}{l}\text { O } \text { Kinect }^{\circledR} \text { não necessita de controle e possui um sensor que viabiliza a } \\
\text { imagem corporal, canais que captam a voz, sistema de câmera, sistema } \\
\text { que capta o movimento, como também o reconhecimento dos pontos } \\
\text { articulares de um ou mais jogadores, favorecendo mais movimentos. }\end{array}$ & $\begin{array}{l}\text { Rocha, } \\
\text { Defaravi } \\
\text { e Brandão } \\
(2012)\end{array}$ \\
\hline Softwares & $\begin{array}{l}\text { Programas de jogos de computador utilizados para pessoas com alguma } \\
\text { dificuldade. Ex.: software de jogo "Só soprando", que proporciona } \\
\text { interação e aprendizagem do usuário através do controle de voz. }\end{array}$ & Fava (2008) \\
\hline Aplicativos & $\begin{array}{l}\text { Aplicativos de jogos de sistemas operacionais. Ex.: aplicativo "Que fala!", } \\
\text { para estimulação oral, ou o aplicativo "SCALA", para estimulação da } \\
\text { comunicação no Autismo. }\end{array}$ & $\begin{array}{l}\text { Santos } \\
\text { Filho et al. } \\
(2012) \\
\text { Bez et al. } \\
(2013)\end{array}$ \\
\hline
\end{tabular}


Oliveira, Silva e Zaparoli (2011, p. 97), em sua pesquisa sobre a utilização de jogos eletrônicos pelo terapeuta ocupacional, dizem que:

O terapeuta ocupacional e educadores precisam observar que as brincadeiras e os brinquedos têm acompanhado a evolução da própria cultura, que avança muito rápido, tendo a tecnologia como fundamento, o que acarreta a utilização do videogame por muitas crianças no Brasil.

Os estudos destacam que a RV, mais especificamente os jogos eletrônicos, pode se tornar recurso terapêutico de diversas áreas da saúde, sobretudo da Terapia Ocupacional, visto que estes são ferramentas importantes para o desenvolvimento humano, no que diz respeito às funçóes motoras, cognitivas e psicoafetivas de pessoas de diversas faixas etárias (OLIVEIRA; SILVA; ZAPAROLI, 2011).

De Grande, Galvão e Gondim (2011) relatam, em seu estudo sobre a utilização de RV na reabilitação, que este método de intervenção simula situaçôes reais importantes para o desempenho ocupacional, tais como para as atividades de vida diária. Pensando nisto, a utilização da RV pela Terapia Ocupacional tanto melhora funçôes cognitivas e motoras do paciente quanto propicia a aprendizagem e o desempenho ocupacional.

O terapeuta ocupacional está diretamente ligado à atividade humana, devendo-se manter atualizado para novas tendências presentes na vida das crianças e dos jovens, a exemplo das tecnologias, pois, a partir destas, observa-se o contexto de cada indivíduo, a fim de estimular as diversas áreas de desempenho ocupacional (OLIVEIRA; SILVA; ZAPAROLI, 2011).

\section{Desempenho ocupacional no ambiente real e virtual}

O desempenho ocupacional pode ser definido como a habilidade que o indivíduo tem de executar papéis e desempenhar rotinas e tarefas, com o objetivo de promover e manter questóes importantes, tais como: autocuidado, produtividade, lazer, etc, para responder às demandas que surgem do meio interno e externo, podendo ser executados também nos contextos e ambientes virtuais (ZANNI et al., 2009 apud CALDAS; FACUNDES; SILVA, 2011; AMERICAN..., 2014).

O ambiente virtual é o ambiente em que a comunicação acontece por meio de computadores (ou demais recursos tecnológicos), em que ocorre a ausência de contato físico, podendo ser por meio de envio de e-mails, conversas em chats, monitoramento remoto através de controles sem fio, dentre outros (AMERICAN..., 2014). Nesse sentido, o contexto virtual diferencia-se do ambiente virtual, ao ponto em que o primeiro estabelece relação com a forma de interação que está sendo estabelecida, enquanto o último denota o ambiente que esta interaçáo ocorre.

Pereira et al. (2007) apud Vianna e Machado (2009) enfocam que novas tecnologias têm sido aplicadas às interfaces de sistemas computacionais para conceber sistemas chamados de hiper-realidade, em que, através de ambientes virtuais, oferecem interação intuitiva e são conectados a ambientes reais remotos.

Em vista disso, essas interfaces desempenham a funçáo de manter uma correspondência entre os ambientes virtuais e respectivos ambientes reais. Schmidt e Lee (1998) apud Perez, Neiva e Monteiro (2014) citam, em seu estudo, uma criança que só jogou boliche no ambiente virtual e, ao se deparar com a situação no ambiente real, teve maior possibilidade de conhecer as etapas e procedimentos que deveria tomar.

No ambiente virtual, é possível vivenciar situações que, às vezes, o indivíduo não tem como executar, a exemplo de uma prática de esqui em uma cidade com o clima tropical. Nestes, e em outros tipos de simulação, o ambiente virtual pode propiciar aprendizagem no desempenho e descobertas de novas sensaçóes, visto que existe a possibilidade de repetir as ações livremente (PEREZ; NEIVA; MONTEIRO, 2014).

Em muitos casos, os procedimentos de reabilitação em ambientes virtuais fazem com que o indivíduo faça o uso de todo o corpo na atividade e não somente de uma habilidade isolada. $\mathrm{O}$ paciente tenta alcançar um objetivo do jogo e desenvolve estratégias de movimento que suportem esse objetivo, influenciando diretamente seu desempenho (ZIJLSTRA et al., 2008). Dessa forma, percebe-se que a RV pode influenciar de maneira significativa no desempenho ocupacional do sujeito, visto que possibilita a aprendizagem obtendo-se ganhos e minimizando possíveis riscos que a atividade no ambiente físico poderia acarretar em algumas situaçôes.

\section{Método}

Trata-se de uma revisão integrativa de literatura da temática proposta, seguindo as normas e etapas de produçáo. Este tipo de pesquisa seleciona estudos relevantes que oferecem suporte para a tomada de decisão e uma prática clínica mais aprimorada, 
sintetizando o estado do conhecimento de um determinado assunto, aprimorando a necessidade de novas pesquisas (MENDES; SILVEIRA; GALVÃO, 2008).

A revisão integrativa é um instrumento da Prática Baseada em Evidências (PBE), caracterizada por uma abordagem que envolve a definiçấo do problema clínico, a identificação de informações, a condução das buscas dos estudos na literatura, a identificação da aplicabilidade dos dados oriundos das publicaçôes e a determinação de sua utilizaçáo para o paciente. Permite a inclusão de estudos experimentais e não experimentais, caracterizando-se como uma abordagem metodológica mais ampla, permitindo que sejam contempladas questôes referentes à Terapia Ocupacional, o que não ocorre nas revisóes sistemáticas e na meta-análise (WHITTEMORE; KNAFL, 2005; ERCOLE; MELO; ALCOFORADO, 2014).

Objetivando-se identificar, analisar e sintetizar resultados de estudos independentes sobre o mesmo assunto, este tipo de revisão apresenta um roteiro para a sua elaboração. Souza, Silva e Carvalho (2010) sintetizam as etapas para elaboração de uma revisão integrativa: a) Elaboração da pergunta norteadora; b) Busca ou amostragem na literatura; c) Coleta de dados; d) Análise crítica dos estudos incluídos; e) Discussão dos resultados; f) Apresentação da revisão integrativa.

Este método vem sendo utilizado em vários estudos na área de saúde, principalmente em enfermagem e fonoaudiologia, com o objetivo de favorecer a melhora das práticas clínicas dessas profissóes (COSCRATO; PINA; MELO, 2010; BUBLITZ et al., 2012; CROSSETTI et al., 2012; LOURENÇO et al., 2012; PROCHNOW et al., 2012; GARUZI et al., 2014; ROSA; BERRETIN-FELIX, 2015).

As etapas do nosso estudo constaram de: 1. Delimitação do tema, das hipóteses, das palavras-chave e dos objetivos; 2. Estabelecimento de critérios de inclusão e exclusão dos textos, e também das bases de dados utilizadas; 3. Categorização e coleta dos estudos; 4. Análise dos achados; 5 . Identificação e discussão dos resultados; 6. Considerações finais; 7. Revisão do texto e finalização.

Foram inclusos os estudos que abordavam o uso da Realidade Virtual dentro da Terapia Ocupacional, publicados entre 2004 e 2014, em línguas portuguesa e inglesa, como artigos completos de periódicos, capítulos de livro eletrônico, dissertaçóes, teses, monografias e artigos completos publicados em anais de congressos. Estes deveriam abordar avaliaçáo, prevenção, promoção, tratamento ou reabilitação, a partir de pesquisas originais, estudos de caso, relatos de experiência ou revisóes da literatura. Foram excluídos os estudos que não estavam completos nas bases de dados; não foram desenvolvidos para o contexto nacional; estudos cujo enfoque se deu nas questôes adaptativas ao uso de equipamentos de realidade virtual, e os capítulos de livros impressos.

Visto se tratar de uma pesquisa em bancos de dados localizados no sítio da web, justifica-se a inclusão de capítulos eletrônicos no presente estudo e a exclusão de capítulos impressos. Este se deu pela inviabilidade no acesso de materiais bibliográficos impressos em nível nacional. No entanto, é de suma importância ressaltar que os estudos advindos de livros e periódicos impressos poderão se somar aos presentes achados digitais.

Para a pesquisa nas bases de dados, foram utilizados os seguintes descritores, palavras-chave, presentes no DeCS (Descritores em Ciências da Saúde) e MeSH (Medical Subject Headings): Terapia Ocupacional, Jogos de Vídeo, Terapia de Exposição à Realidade Virtual, Terapia Assistida por Computador e Interface Usuário-computador. Utilizaram-se também termos livres, palavras-chave não encontradas no DeCS/MeSH, mas de importância para a busca dos artigos: 'Realidade Virtual', 'Reabilitação Virtual', 'Wii Terapia', 'Jogos Eletrônicos' e 'Virtual'.

Realizou-se uma pesquisa utilizando-se descritores combinados (Tabela 2) nas bases de dados do Portal CAPES, LILACS e MEDLINE, através das plataformas PUBMED e BIREME. Individualmente, foram analisados os bancos de dados do SciELO

Tabela 2. Descritores e termos livres combinados utilizados na busca dos estudos.

\author{
Jogos eletrônicos AND Terapia Ocupacional; \\ Jogos de vídeo AND Terapia Ocupacional; \\ Terapia Ocupacional AND Virtual; \\ Realidade Virtual AND Reabilitação; \\ Wii AND Terapia Ocupacional; \\ Wii AND Reabilitação; \\ Terapia de Exposição à Realidade Virtual AND Terapia Ocupacional; \\ Reabilitação Virtual AND Terapia Ocupacional. \\ Terapia Assistida por Computador AND Terapia Ocupacional \\ Interface Usuário-Computador AND Terapia Ocupacional
}

Descritores combinados utilizados segundo o operador booleano 'AND'. 
e periódicos de enfoque da Terapia Ocupacional (Revista de Terapia Ocupacional da USP e Cadernos de Terapia Ocupacional da UFSCar). De modo complementar, foi realizada uma busca livre no Scholar Google, no qual foram localizados outros estudos que constavam em meios não indexados, como: base de dados de programas de pós-graduação, anais de congressos, monografias e capítulos de livros digitais.

Os descritores foram utilizados no idioma português, visto que o objetivo era identificar publicaçôes voltadas ao contexto nacional; no entanto, náo se excluíram os estudos que estivessem em inglês e que tivessem sido idealizados no Brasil.

Foi elaborado um instrumento norteador para responder aos questionamentos, categorizar e analisar a coleta de informaçôes. As dicotomias categóricas foram: autores, ano de publicação, desenho metodológico, tipo de intervenção, amostra pesquisada, faixa-etária pesquisada, profissionais das pesquisas, abordagem utilizada, equipamento utilizado e resultados obtidos.

\section{Resultados e Discussão}

Foram encontrados, inicialmente, 1.271 estudos com a temática proposta; dentre estes, foram excluídos 1.238 estudos, de acordo com os critérios de exclusão estabelecidos. Após a aplicação dos critérios de elegibilidade, restaram 33 estudos, sendo 18 repetidos nas bases. Dessa forma, 15 estudos foram selecionados e são apresentados, em sua forma global, na Figura 1, na Tabela 3 os estudos podem ser visualizados separadamente, categorizados pelos itens: título, autoria, meio de publicação e ano de publicação.

O processo de seleção dos estudos pode ser mais bem visualizado na Figura 1.

Para a discussão destes estudos, foi utilizado um banco de dados que serviu para a categorização das informaçóes, seguindo a mesma sequência de numeração dos estudos apresentados na Tabela 3, sendo divididos nas categorias: desenho metodológico, tipo de intervenção, amostra pesquisada, faixa-etária, abordagem utilizada e resultados obtidos, que pode ser visualizado na Tabela 4 .

Ao analisar as publicaçóes, percebeu-se que a maior parte dos estudos foi divulgada no ano de 2011, num total de cinco publicaçôes $(33,3 \%)$; observou-se uma em 2004 (6,6\%), duas em 2006 (13,3\%), seguidas de duas publicaçôes em 2008 (13,3\%), três em 2010 (20\%) e duas em 2013 (13,3\%). Nos demais anos, náo foi encontrado nenhum estudo. Pode-se observar a histografia de publicaçóes na Figura 2, abaixo.

Percebe-se uma variação da continuidade, mas um aumento das publicaçóes entre os anos, apenas com uma diminuição em 2013, como também uma alternância entre os anos pares e ímpares. Tal desenvolvimento de estudos pode estar diretamente relacionado à própria atualização da tecnologia, que possibilitou o acesso das pessoas aos meios digitais, influenciando diretamente na construção de estudos científicos que utilizam essa abordagem.

Quando a inclusão digital foi inserida no Brasil, aproximadamente em 2000, trouxe consigo as Tecnologias de Informação e Comunicação (TIC), um programa que permite envolver pessoas na era digital, tendo como premissa a busca da garantia
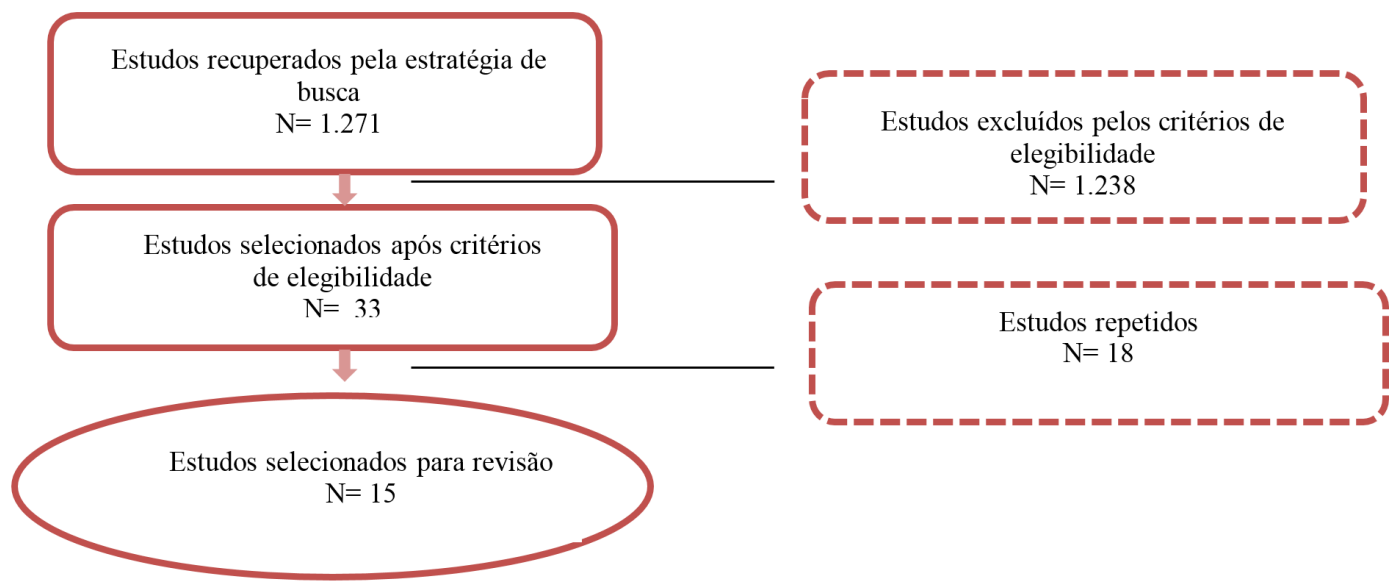

Figura 1. Fluxograma do número de estudos encontrados e selecionados após aplicação dos critérios de inclusão e exclusão. 
Tabela 3. Estudos selecionados para a revisão.

\begin{tabular}{|c|c|c|c|}
\hline & TÍTULO & AUTOR(ES) & $\begin{array}{c}\text { MEIO DE } \\
\text { PUBLICAÇÃO }\end{array}$ \\
\hline 01. & $\begin{array}{l}\text { Desenvolvimento de Jogos de Computador } \\
\text { como Atividade Terapêutica no Tratamento de } \\
\text { Dependentes Químicos. }\end{array}$ & $\begin{array}{l}\text { Silva, Frère e Oliveira } \\
(2004)\end{array}$ & Anais de Congresso \\
\hline 02. & $\begin{array}{l}\text { Utilização de jogos pela terapia ocupacional: } \\
\text { contribuição para a reabilitação cognitiva. }\end{array}$ & Muragaki et al. (2006) & Anais de Congresso \\
\hline 03. & $\begin{array}{l}\text { Iniciação ao uso do computador: um relato de } \\
\text { experiência com crianças com paralisia cerebral. }\end{array}$ & $\begin{array}{l}\text { Lima, Marino e Palhares } \\
(2006)\end{array}$ & $\begin{array}{l}\text { Cadernos } \\
\text { de Terapia } \\
\text { Ocupacional da } \\
\text { UFSCar }\end{array}$ \\
\hline 04. & $\begin{array}{l}\text { Terapia Ocupacional em Ação Interdisciplinar: } \\
\text { Jogos Educativo-nutricionais na prevenção da } \\
\text { obesidade infantil. }\end{array}$ & Munguba (2008) & PPG UFRN \\
\hline 05. & $\begin{array}{l}\text { Jogando com o ar: o sopro como instrumento de } \\
\text { acessibilidade nos jogos eletrônicos. }\end{array}$ & Fava (2008) & Anais de Congresso \\
\hline 06. & $\begin{array}{l}\text { Educação na saúde - sobreposição de saberes ou } \\
\text { interface? }\end{array}$ & Munguba (2010) & $\begin{array}{l}\text { Revista Brasileira } \\
\text { de Promoção da } \\
\text { Saúde (CAPES). }\end{array}$ \\
\hline 07. & $\begin{array}{l}\text { Estudo do uso de softwares e recursos de acesso ao } \\
\text { computador para pacientes com Distrofia Muscular } \\
\text { de Duchenne. }\end{array}$ & Oliveira et al. (2010b) & $\begin{array}{l}\text { Cadernos } \\
\text { de Terapia } \\
\text { Ocupacional da } \\
\text { UFSCar }\end{array}$ \\
\hline 08. & $\begin{array}{l}\text { Evaluation of cognitive technologies in geriatric } \\
\text { rehabilitation: a case study pilot project. }\end{array}$ & Oliveira et al. (2010a) & $\begin{array}{l}\text { Occupational } \\
\text { Therapy } \\
\text { International } \\
\text { (BIREME) }\end{array}$ \\
\hline 09. & $\begin{array}{l}\text { Jogo Eletrônico mediando a inclusão de pessoas } \\
\text { com deficiência intelectual no mundo do trabalho. }\end{array}$ & Oliveira e Munguba (2011) & $\begin{array}{l}\text { Revista de Iniciação } \\
\text { Científica da FFC }\end{array}$ \\
\hline 10. & Inovação tecnológica e Inclusão Social. & $\begin{array}{l}\text { Oliveira, Silva e Zaparoli } \\
(2011)\end{array}$ & $\begin{array}{l}\text { Capítulo de livro } \\
\text { digital }\end{array}$ \\
\hline 11. & $\begin{array}{l}\text { Realidade Aumentada Musical para Reabilitação: } \\
\text { Estudo de caso em musicoterapia. }\end{array}$ & Correa (2011) & $\begin{array}{l}\text { Revista de Terapia } \\
\text { Ocupacional da } \\
\text { USP. }\end{array}$ \\
\hline 12. & Realidade Virtual na Paralisia Cerebral. & Monteiro (2011) & $\begin{array}{l}\text { Capítulo de livro } \\
\text { digital }\end{array}$ \\
\hline 13. & $\begin{array}{l}\text { Reabilitação virtual através do videogame: relato } \\
\text { de caso no tratamento de um paciente com lesão } \\
\text { alta dos nervos mediano e ulnar. }\end{array}$ & $\begin{array}{l}\text { Grande, Galvão e Gondim } \\
\text { (2011) }\end{array}$ & $\begin{array}{l}\text { Periódico Acta } \\
\text { Fisiátrica }\end{array}$ \\
\hline 14. & $\begin{array}{l}\text { Eficácia da realidade virtual no tratamento } \\
\text { de crianças com paralisia cerebral - revisão } \\
\text { sistemática. }\end{array}$ & Carvalho (2013) & $\begin{array}{l}\text { Monografia } \\
\text { publicada em meio } \\
\text { eletrônico }\end{array}$ \\
\hline 15. & $\begin{array}{l}\text { Análise da frequência cardíaca de adultos jovens } \\
\text { saudáveis durante performance em um jogo de } \\
\text { realidade virtual de imersão. }\end{array}$ & Barbosa (2013) & $\begin{array}{l}\text { Cadernos } \\
\text { de Terapia } \\
\text { Ocupacional da } \\
\text { UFSCar. }\end{array}$ \\
\hline
\end{tabular}

de acesso das pessoas às informaçôes através da tecnologia, de modo que isto sirva também como forma de solução para problemas sociais, possibilidades de emprego, como também para qualidade de vida (MATTOS; SANTOS, 2009). Acredita-se que este aspecto alavancou o interesse dos pesquisadores, a fim de novas descobertas relacionadas também ao uso deste equipamento voltado para a área da saúde.
Considerando-se o tipo de publicação em cada estudo, encontramos nove artigos (60\%), dois capítulos de livros digitais $(13,3 \%)$, duas teses $(13,3 \%)$, uma dissertação $(6,6 \%)$ e uma monografia $(6,6 \%)$, sendo todos publicados em revistas científicas.

Dentre as bases de dados em que foram encontradas (Figura 3), observamos estudos publicados em periódicos de importância para a Terapia Ocupacional, 
Tabela 4. Categorização para análise dos estudos.

\begin{tabular}{|c|c|c|c|c|c|c|}
\hline $\mathbf{N}^{\circ}$ & $\begin{array}{l}\text { Desenho } \\
\text { metodológico }\end{array}$ & $\begin{array}{c}\text { Tipo de } \\
\text { intervenção }\end{array}$ & $\begin{array}{c}\text { Amostra } \\
\text { pesquisada }\end{array}$ & Faixa-etária & $\begin{array}{c}\text { Objetivo e } \\
\text { abordagem utilizada }\end{array}$ & Resultados obtidos \\
\hline 1 & $\begin{array}{l}\text { Relato } \\
\text { de } \\
\text { experiência }\end{array}$ & Prevenção & $\begin{array}{l}\text { Dependentes } \\
\text { químicos }\end{array}$ & 17 a 38 anos & $\begin{array}{l}\text { Uso da interface } \\
\text { computadorizada } \\
\text { como recurso } \\
\text { terapêutico para } \\
\text { redução de ansiedade. }\end{array}$ & $\begin{array}{l}\text { Percebeu-se que o } \\
\text { uso dos recursos de } \\
\text { tecnologia provocou } \\
\text { nos usuários } \\
\text { um pensamento } \\
\text { desfocado da droga, } \\
\text { enriquecendo seus } \\
\text { pensamentos e } \\
\text { fantasias. }\end{array}$ \\
\hline 2 & $\begin{array}{l}\text { Publicação } \\
\text { original }\end{array}$ & Avaliação & $\begin{array}{l}\text { Indivíduos } \\
\text { com déficit } \\
\text { cognitivo }\end{array}$ & $\begin{array}{l}\text { Não se } \\
\text { aplica }\end{array}$ & $\begin{array}{l}\text { Análise de jogos de } \\
\text { computador próprios } \\
\text { da Microsoft Windows } \\
\text { (paciência, campo } \\
\text { minado, freecell) para } \\
\text { reabilitação cognitiva. }\end{array}$ & $\begin{array}{l}\text { Os jogos são } \\
\text { importantes recursos } \\
\text { por serem atividades } \\
\text { lúdicas que podem } \\
\text { ser indicadas para } \\
\text { diferentes idades, } \\
\text { visando à reabilitação } \\
\text { cognitiva. }\end{array}$ \\
\hline 3 & $\begin{array}{l}\text { Estudo } \\
\text { de caso }\end{array}$ & Avaliação & $\begin{array}{l}\text { Crianças e } \\
\text { adolescentes } \\
\text { com } \\
\text { paralisia } \\
\text { cerebral }\end{array}$ & 12 a 17 anos & $\begin{array}{l}\text { Uso de jogos } \\
\text { eletrônicos, antes } \\
\text { e apos intervenção } \\
\text { terapêutica } \\
\text { ocupacional } \\
\text { para analise do } \\
\text { desempenho } \\
\text { ocupacional de } \\
\text { indivíduos com } \\
\text { paralisia cerebral. }\end{array}$ & $\begin{array}{l}\text { Percebeu-se } \\
\text { necessidade da } \\
\text { comunidade } \\
\text { acadêmica em se } \\
\text { aprofundar em estudos } \\
\text { relacionados, pois os } \\
\text { jogos são benéficos } \\
\text { para o lazer e a } \\
\text { reabilitação. }\end{array}$ \\
\hline 4 & $\begin{array}{l}\text { Publicação } \\
\text { original }\end{array}$ & Prevenção & $\begin{array}{l}200 \text { crianças } \\
\text { sob risco de } \\
\text { obesidade }\end{array}$ & 12 a 14 anos. & $\begin{array}{l}\text { Uso de jogos } \\
\text { educativos- } \\
\text { nutricionais para } \\
\text { prevenção de } \\
\text { obesidade. }\end{array}$ & $\begin{array}{l}\text { Os jogos podem } \\
\text { ser utilizados na } \\
\text { aprendizagem sobre } \\
\text { conceitos nutricionais. }\end{array}$ \\
\hline 5 & $\begin{array}{l}\text { Relato } \\
\text { de } \\
\text { Experiência }\end{array}$ & $\begin{array}{l}\text { Promoção de } \\
\text { saúde }\end{array}$ & $\begin{array}{l}\text { Crianças } \\
\text { com } \\
\text { paralisia } \\
\text { cerebral }\end{array}$ & 04 anos & $\begin{array}{l}\text { Utilização do } \\
\text { computador e } \\
\text { seus recursos } \\
\text { para promoção de } \\
\text { saúde, inclusão e } \\
\text { acessibilidade para } \\
\text { crianças com paralisia } \\
\text { cerebral. }\end{array}$ & $\begin{array}{l}\text { É possível promover } \\
\text { a inclusão através } \\
\text { deste recurso, como } \\
\text { também há melhora } \\
\text { nas habilidades e } \\
\text { aquisições para a } \\
\text { independência. }\end{array}$ \\
\hline 6 & $\begin{array}{l}\text { Publicação } \\
\text { original }\end{array}$ & $\begin{array}{l}\text { Promoção de } \\
\text { Saúde }\end{array}$ & $\begin{array}{l}\text { Profissionais } \\
\text { de saúde e } \\
\text { educação }\end{array}$ & $\begin{array}{l}\text { Não se } \\
\text { aplica }\end{array}$ & $\begin{array}{l}\text { Informar o benefício } \\
\text { do uso da abordagem } \\
\text { lúdica dos jogos } \\
\text { eletrônicos na } \\
\text { educação e saúde }\end{array}$ & $\begin{array}{l}\text { É possível intervir na } \\
\text { educação e na saúde } \\
\text { por meio de jogos } \\
\text { eletrônicos. }\end{array}$ \\
\hline 7 & $\begin{array}{l}\text { Publicação } \\
\text { original }\end{array}$ & Avaliação & $\begin{array}{l}\text { Indivíduos } \\
\text { com } \\
\text { Distrofia } \\
\text { Muscular de } \\
\text { Duchenne }\end{array}$ & 16 a 24 anos & $\begin{array}{l}\text { Verificar a } \\
\text { aplicabilidade de } \\
\text { softwares e periféricos } \\
\text { de computador em } \\
\text { indivíduos com DMD. }\end{array}$ & $\begin{array}{l}\text { Os recursos testados } \\
\text { demonstram potencial } \\
\text { de aplicabilidade para } \\
\text { esta população. }\end{array}$ \\
\hline
\end{tabular}


Tabela 4. Continuação...

\begin{tabular}{|c|c|c|c|c|c|c|}
\hline $\mathbf{N}^{\circ}$ & $\begin{array}{c}\text { Desenho } \\
\text { metodológico }\end{array}$ & $\begin{array}{c}\text { Tipo de } \\
\text { intervenção }\end{array}$ & $\begin{array}{c}\text { Amostra } \\
\text { pesquisada }\end{array}$ & Faixa-etária & $\begin{array}{c}\text { Objetivo e } \\
\text { abordagem utilizada }\end{array}$ & Resultados obtidos \\
\hline 8 & $\begin{array}{l}\text { Estudo } \\
\text { de caso }\end{array}$ & Reabilitação & $\begin{array}{l}\text { Idoso com } \\
\text { demência }\end{array}$ & 73 anos & $\begin{array}{l}\text { Utilização de software } \\
\text { que inclui jogos, } \\
\text { exercícios, calendário } \\
\text { e testes para } \\
\text { reabilitação cognitiva } \\
\text { em idosos. }\end{array}$ & $\begin{array}{l}\text { Foi comprovada } \\
\text { a utilidade para a } \\
\text { prática descrita, sendo } \\
\text { possível envolver o } \\
\text { paciente e sua atenção } \\
\text { na atividade. }\end{array}$ \\
\hline 9 & $\begin{array}{l}\text { Publicação } \\
\text { original }\end{array}$ & Avaliação & $\begin{array}{l}\text { Jovens e } \\
\text { adultos com } \\
\text { deficiência } \\
\text { intelectual }\end{array}$ & 16 a 30 anos. & $\begin{array}{l}\text { Uso de games na } \\
\text { aprendizagem de } \\
\text { conceitos pedagógicos } \\
\text { para a preparação para } \\
\text { o mundo do trabalho. }\end{array}$ & $\begin{array}{l}\text { Percebeu-se } \\
\text { aprendizagem dos } \\
\text { conceitos pedagógicos } \\
\text { focados no ingresso } \\
\text { de jovens e adultos } \\
\text { com deficiência } \\
\text { intelectual no mundo } \\
\text { do trabalho. }\end{array}$ \\
\hline 10 & $\begin{array}{l}\text { Publicação } \\
\text { original }\end{array}$ & $\begin{array}{l}\text { Promoção de } \\
\text { Saúde }\end{array}$ & $\begin{array}{l}\text { Indivíduos } \\
\text { com } \\
\text { deficiência } \\
\text { física e/ou } \\
\text { cognitiva }\end{array}$ & $\begin{array}{l}\text { Diversas } \\
\text { faixas etárias }\end{array}$ & $\begin{array}{l}\text { Uso de um jogo } \\
\text { eletrônico para } \\
\text { promover interação } \\
\text { e socialização de } \\
\text { indivíduos com } \\
\text { deficiência. }\end{array}$ & $\begin{array}{l}\text { É possível aumentar/ } \\
\text { criar vínculos de } \\
\text { interação social, } \\
\text { através de habilidades } \\
\text { desempenhadas no } \\
\text { jogo. }\end{array}$ \\
\hline 11 & $\begin{array}{l}\text { Publicação } \\
\text { original }\end{array}$ & Reabilitação & $\begin{array}{l}\text { Paciente em } \\
\text { tratamento } \\
\text { de } \\
\text { reabilitação } \\
\text { motora }\end{array}$ & 5 anos & $\begin{array}{l}\text { Uso de gamesoftwares } \\
\text { para auxiliar a } \\
\text { reabilitação através da } \\
\text { musicoterapia. }\end{array}$ & $\begin{array}{l}\text { Percebeu-se satisfação } \\
\text { semelhante ao uso de } \\
\text { instrumentos reais na } \\
\text { reabilitação. }\end{array}$ \\
\hline
\end{tabular}

\begin{tabular}{|c|c|c|c|c|c|c|}
\hline 12 & $\begin{array}{l}\text { Publicação } \\
\text { original }\end{array}$ & Avaliação & $\begin{array}{l}\text { Indivíduos } \\
\text { com } \\
\text { Síndrome de } \\
\text { Down }\end{array}$ & 11 a 18 anos & $\begin{array}{l}\text { Verificar o nível de } \\
\text { aprendizagem motora } \\
\text { em indivíduos com } \\
\text { SD, através de jogos } \\
\text { eletrônicos. }\end{array}$ & $\begin{array}{l}\text { Foi possível } \\
\text { perceber resultados } \\
\text { funcionais positivos, } \\
\text { apresentando bom } \\
\text { desempenho na } \\
\text { atividade. }\end{array}$ \\
\hline 13 & $\begin{array}{l}\text { Estudo } \\
\text { de caso }\end{array}$ & Reabilitação & $\begin{array}{l}\text { Paciente } \\
\text { com lesão } \\
\text { alta dos } \\
\text { nervos } \\
\text { mediano e } \\
\text { ulnar }\end{array}$ & 9 anos & $\begin{array}{l}\text { Uso do Nintendo } \\
\text { Wii para comparar } \\
\text { graus de Amplitude } \\
\text { de Movimento das } \\
\text { articulações do } \\
\text { membro lesado. }\end{array}$ & $\begin{array}{l}\text { O videogame é eficaz } \\
\text { no ganho de ADM, } \\
\text { como também ganho } \\
\text { de independência nas } \\
\text { AVDs. }\end{array}$ \\
\hline 14 & $\begin{array}{l}\text { Artigo } \\
\text { de revisão } \\
\text { sistemática }\end{array}$ & Avaliação & $\begin{array}{l}\text { Publicações } \\
\text { entre 2003 } \\
\text { e 2013, em } \\
\text { português, } \\
\text { inglês e } \\
\text { espanhol. } \\
\text { Nas bases de } \\
\text { dados BVS, } \\
\text { Sciello e } \\
\text { PubMed }\end{array}$ & & $\begin{array}{l}\text { Estudos que } \\
\text { contemplassem } \\
\text { o uso da RV para } \\
\text { o tratamento da } \\
\text { Paralisia Cerebral. }\end{array}$ & $\begin{array}{l}\text { Foram encontrados } \\
125 \text { artigos sobre } \\
\text { o uso da RV no } \\
\text { tratamento da PC. } \\
\text { Destes, apenas } \\
\text { seis estudos foram } \\
\text { incluídos, seguindo } \\
\text { critérios de inclusão } \\
\text { e exclusão pré- } \\
\text { estabelecidos. }\end{array}$ \\
\hline 15 & $\begin{array}{l}\text { Ensaio } \\
\text { Clínico }\end{array}$ & Avaliação & $\begin{array}{l}\text { Adultos } \\
\text { jovens } \\
\text { saudáveis }\end{array}$ & 18 a 30 anos & $\begin{array}{l}\text { Avaliação da } \\
\text { frequência cardíaca } \\
\text { causada por uma } \\
\text { sessão do jogo de } \\
\text { boxe. }\end{array}$ & $\begin{array}{l}\text { A frequência } \\
\text { cardíaca vai de leve } \\
\text { à moderada e é um } \\
\text { jogo seguro para ser } \\
\text { usado como recurso } \\
\text { terapêutico. }\end{array}$ \\
\hline
\end{tabular}




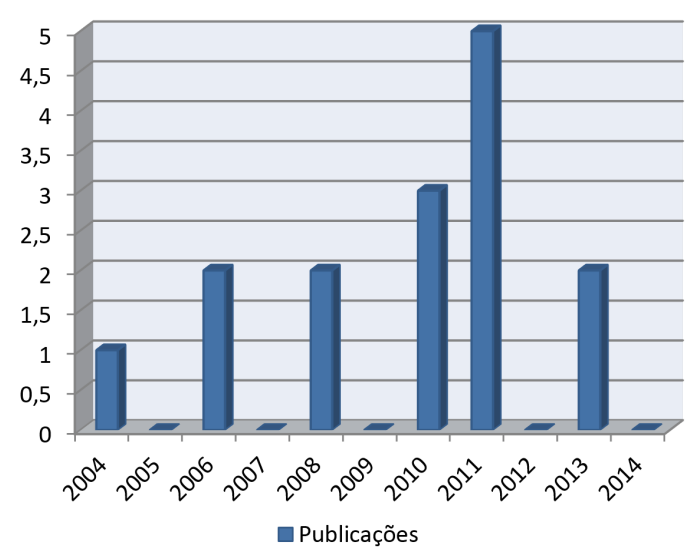

Figura 2. Numero de publicações entre 2004 e 2014.

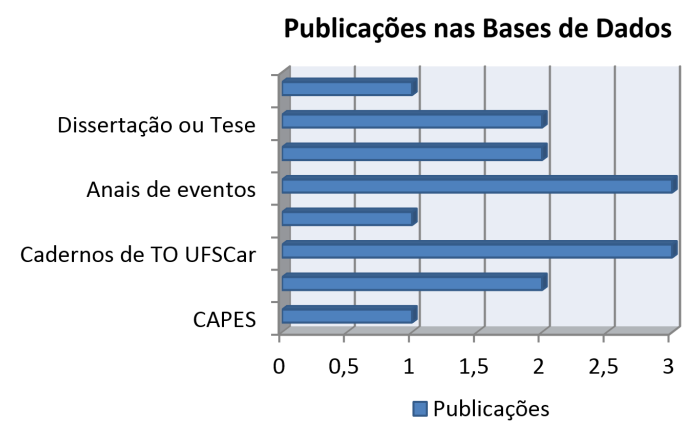

Figura 3. Publicações encontradas nas bases de dados entre 2004 e 2014.

como os Cadernos de Terapia Ocupacional da UFSCar ( $\mathrm{n}=3 ; 20 \%)$, anais de eventos científicos $(\mathrm{n}=3 ; 20 \%)$, BIREME $(\mathrm{n}=2 ; 13,3 \%)$, capítulos de livros digitais $(\mathrm{n}=2 ; 13,3 \%)$ e Programas de pós-graduação $(\mathrm{n}=2 ; 13,3 \%)$, no portal de Periódicos da CAPES ( $\mathrm{n}=1 ; 6,6 \%$ ), além da Revista de Terapia Ocupacional da USP (n=1; 6,6\%) e um artigo em revista não indexada através de busca livre (6,6\%).

De acordo com os descritores utilizados a partir do DeCS e MeSH, os únicos encontrados foram: "Terapia Ocupacional" em sete publicaçôes e "Jogos de Vídeo” em duas publicaçóes. Percebeu-se que a maioria estava relacionada a termos livres, como: "Reabilitação" ( $\mathrm{n}=4$ ), "Realidade Virtual" ( $\mathrm{n}=1)$ e "Jogos eletrônicos" ( $\mathrm{n}=1)$. Observamos também a utilizaçáo de outros termos importantes, que inicialmente não foram proposta de busca e que podem ser observados na Tabela 5, a seguir. Dois estudos náo utilizavam palavras-chave, pois se apresentam como capítulo de livro digital e artigo publicado em editorial.
Tabela 5. Palavras-chave encontradas nos estudos.

\begin{tabular}{|c|c|c|c|}
\hline \multicolumn{4}{|c|}{ Palavras-chave } \\
\hline $\begin{array}{l}\text { Descritores DeCS e } \\
\text { MeSH encontrados }\end{array}$ & (n) & Termos Livres & (n) \\
\hline Terapia Ocupacional & 7 & Reabilitação & 4 \\
\hline \multirow[t]{20}{*}{ Jogos de Vídeo } & 2 & $\begin{array}{l}\text { Tecnologia } \\
\text { Assistiva }\end{array}$ & 2 \\
\hline & & Realidade Virtual & 1 \\
\hline & & Jogos eletrônicos & 1 \\
\hline & & Jogos & 1 \\
\hline & & Tecnologia & 1 \\
\hline & & Jogos e & 1 \\
\hline & & Brinquedos & \\
\hline & & Controle & 1 \\
\hline & & Tecnológico do & \\
\hline & & Ambiente & \\
\hline & & Sistemas & 1 \\
\hline & & Interativos & \\
\hline & & Realidade & 1 \\
\hline & & Aumentada & \\
\hline & & Jogos por & 1 \\
\hline & & Computador & \\
\hline & & Teoria do Jogo & 1 \\
\hline & & Computador & 1 \\
\hline & & Terapia de & 1 \\
\hline & & $\begin{array}{l}\text { Realidade Virtual } \\
\text { de Imersão }\end{array}$ & \\
\hline
\end{tabular}

Dois destes estudos apresentaram como palavras-chave o termo "Tecnologia Assistiva" (13,3\%), que, segundo Bersch (2013), diz respeito ao arsenal de equipamentos/serviços que possibilita a realização da função desejada, que foi impedida por desordens motoras, neurológicas ou de envelhecimento. Isso se torna um fator importante para ser levado em consideração, visto que existe a possibilidade de haver um engano por parte dos pesquisadores ao relacionar a Realidade Virtual com a Tecnologia Assistiva, podendo dificultar a possibilidade de busca nos periódicos para estudos posteriores.

Ao considerar o desenho metodológico dos estudos, temos que a pesquisa mais utilizada ainda é a que visa a publicaçóes originais, ao ponto que os demais resultados são apresentados na Tabela 6 , a seguir.

Ao analisar o tipo de intervençáo no qual as pesquisas encontradas utilizaram a $R V$, encontramos que o maior quantitativo estava ligado a finalidades avaliativas, contendo sete estudos $(46,6 \%)$; três estudos são voltados à promoção de saúde (20\%), três utilizaram a abordagem em tratamento de reabilitação $(20 \%)$ e dois estudos são voltados à prevençáo de riscos relacionados à saúde (13,3\%). 
Tabela 6. Publicações quanto ao desenho metodológico.

\begin{tabular}{lcc}
\multicolumn{1}{c}{\begin{tabular}{c}
\multicolumn{1}{c}{ Desenho } \\
metodológico
\end{tabular}} & \multicolumn{2}{c}{ Publicações selecionadas } \\
\cline { 2 - 3 } & (n) & $\mathbf{( \% )}$ \\
\hline $\begin{array}{l}\text { Publicações } \\
\text { originais }\end{array}$ & 08 & $53,4 \%$ \\
$\begin{array}{l}\text { Estudos de caso } \\
\text { Relato de }\end{array}$ & 03 & $20 \%$ \\
experiência & 02 & $13,3 \%$ \\
Artigos de revisão & 01 & \\
Ensaio Clínico & 01 & 6,6 \\
\hline
\end{tabular}

Observou-se que a maior parte dos estudos buscou avaliar desde o impacto positivo que os equipamentos de Realidade Virtual podem causar na saúde - tais como aspectos de adaptabilidade e funcionalidade para os pacientes - até a avaliação dos componentes de desempenho de cada pessoa (cognitivo, motor, dentre outros), na utilização dos equipamentos. Acredita-se que a ênfase maior se dá na avaliação pelo recente uso do método nas intervençôes, tendendo-se a avaliar e certificar o benefício para entâo intervir.

O terapeuta ocupacional é um profissional formado para avaliar o paciente em todos os seus aspectos de desempenho, visando a suas potencialidades para assim também avaliar e escolher qual recurso ou método é mais eficaz em seu tratamento. O profissional é responsável por realizar avaliaçóes e, com base nisto, organizar e gerenciar o programa terapêutico, verificando os reais benefícios propiciados ao indivíduo (MONTEIRO, 2011). Note-se que este é um fator importante para o êxito da intervenção.

Analisando-se as regiôes brasileiras, nas quais foram desenvolvidos os estudos, observamos uma grande concentração no Sudeste ( $\mathrm{n}=9 ; 60 \%)$, em São Paulo e Minas Gerais; em seguida, observamos a Região Nordeste $(n=4 ; 26,6 \%)$, no Ceará e Rio Grande do Norte. Também houve estudos desenvolvidos na região Centro-Oeste, no Distrito Federal ( $\mathrm{n}=1 ; 6,6 \%)$, e na Região Norte, no Pará ( $\mathrm{n}=1 ; 6,6 \%)$. Na Regiāo Sul, não foi desenvolvido nenhum estudo. Tal distribuição pode ser visualizada na Figura 4.

O Sudeste é uma região reconhecida por ser o centro de desenvolvimento da economia e da produção, também sendo a região em que predominam os estudos científicos sobre o uso da Realidade Virtual pela Terapia Ocupacional, o que pode ocorrer devido ao maior número de profissionais e cursos de formação. Segundo o Ministério da Educação (BRASIL, 2014), o Sudeste é a regiáo que mais possui cursos de Terapia Ocupacional. No país, existem, atualmente, 80 cursos de Terapia Ocupacional, sendo o Sudeste responsável por 40 cursos - portanto, 50\% deste

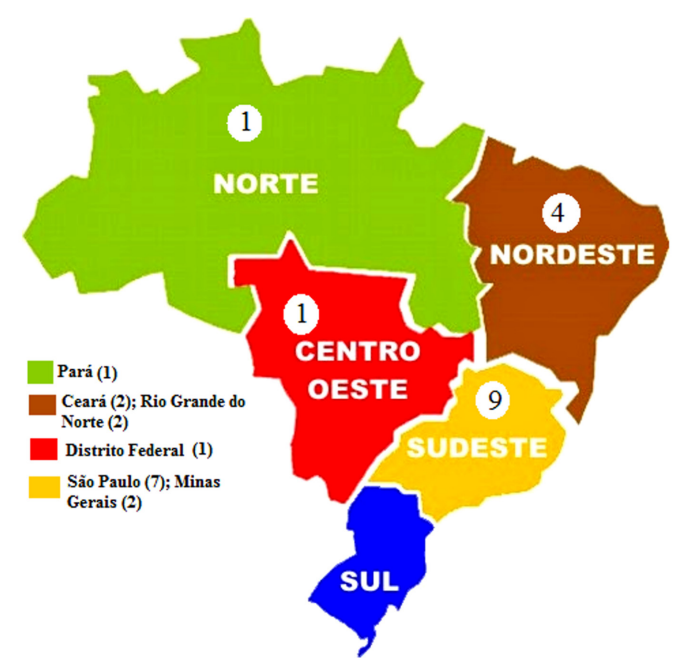

Figura 4. Distribuição de estudos em RV e TO por Região do Brasil.

quantitativo, seguido do Nordeste, com 15 cursos, e os demais, distribuídos nas outras regióes.

O crescimento da produção científica no Nordeste também vem se destacando nos últimos anos. Segundo o Conselho Nacional de Desenvolvimento Científico e Tecnológico (CONSELHO..., 2006), a região registrou um índice de crescimento entre os grupos de pesquisa e produçóes científicas no país, tendo como um forte indicativo a presença dos eventos científicos relacionados à área.

Em relação à faixa etária mais presente, na qual foi utilizada a RV, encontra-se uma maior porcentagem em adolescentes e adultos jovens ( $n=7 ; 46,6 \%)$, seguidos de crianças $(\mathrm{n}=3 ; 20 \%)$ e idosos $(\mathrm{n}=1 ; 6,6 \%)$; existiram também estudos que utilizavam abordagens em diversas faixas etárias $(\mathrm{n}=4 ; 26,6 \%)$. Conforme normalmente é observado, o uso de jogos, seja nos videogames ou em computadores, é mais notório na população jovem; assim, apesar de ter crescido nas outras faixas etárias, os jovens continuam assíduos em interesse nessa utilização.

Fortin (2006), em seu estudo sobre o interesse da população jovem no mundo virtual, destacou que os adolescentes e jovens, dos anos 1980 até atualmente, já nasceram inseridos em um meio digital e que, consequentemente, a vida virtual faz parte do cotidiano destes; dentre muitos atrativos da rede, os jogos eletrônicos ainda são os que mais fascinam os jovens.

Dentre os profissionais que utilizaram a RV em suas pesquisas, o terapeuta ocupacional estava presente em todas elas $(\mathrm{n}=15 ; 100 \%)$, visto que era um critério para inclusão dos estudos. Entretanto, também foram 
encontradas pesquisas de caráter multiprofissional $(n=5 ; 33,4 \%)$, nas quais se observou a presença de nutricionista, médico, game designer, engenheiro mecânico, fisioterapeuta, acadêmicos de Enfermagem, estagiário de Pedagogia e musicoterapeuta.

Considerando-se os equipamentos utilizados, observamos que o maior uso concentra-se nos softwares de computadores $(\mathrm{n}=10 ; 66,6 \%)$, seguindo-se do uso do videogame Nintendo $W_{i i}{ }^{\circledR}$ (n= 4; 26,6\%); um estudo náo definiu um tipo de console, abordando questóes do uso de equipamentos em geral.

Acredita-se que o computador seja o equipamento mais utilizado devido ao crescimento da venda e do consumo. A Pesquisa Nacional por Amostra de Domicílios (PNAD), divulgada pelo Instituto Brasileiro de Geografia e Estatística (IBGE), mostra que o total de domicílios com computadores subiu de 46,4\% para 49,5\%, de 2012 para 2013 (INSTITUTO..., 2013). Aspectos, como apoio midiático, aparelhos de múltiplas funções e preços que se tornaram mais acessíveis são alguns exemplos de fatores que influenciam nesse crescimento.

Watanabe, Tsukimoto e Tsukimoto (2003), em seu estudo sobre o uso do computador como um recurso da Terapia Ocupacional, consideram que a utilização desse equipamento e suas aplicaçóes tornam-se parte do processo de intervenção, visto que amplia as possibilidades de interação de diferentes aspectos a serem trabalhados e que envolvem: aspectos motores, perceptocognitivos, comunicação, acesso a informaçôes, autonomia, interesses do paciente e até mesmo lazer, promovendo a convivência e a reinserção do sujeito na cultura e na sociedade

Quanto à amostra pesquisada e, a partir dos objetivos do uso da RV e seus resultados, pode-se observar que a maior parte dos pesquisadores utilizou a Realidade Virtual para intervir em desordens neurológicas e motoras ( $\mathrm{n}=11 ; 73,3 \%$ ), por exemplos: na Paralisia Cerebral (MONTEIRO, 2011), na Distrofia Muscular de Duchenne (OLIVEIRA et al., 2010b), dentre outras, sendo utilizada para promover participação social, reabilitação motora e cognitiva em crianças, jovens e idosos. Esse fato pode ser explicado por sua eficácia na resposta ao tratamento, cada vez mais comprovada nos estudos, o que estimula o interesse dos pesquisadores.

Os demais estudos estavam voltados para prevenção de crianças em risco de obesidade $(n=1 ; 6,6 \%)$, prevençáo de transtorno de ansiedade em dependentes químicos $(n=1 ; 6,6 \%)$, aplicabilidade de jogo em jovens saudáveis para teste de segurança ( $n=1 ; 6,6 \%)$ e utilização da RV voltada para educação permanente de profissionais da saúde e da educação
( $\mathrm{n}=1 ; 6,6 \%)$. Em todos os estudos, foi comprovada a eficácia da utilizaçáo deste recurso, cumprindo os objetivos propostos.

\section{Conclusão}

Conclui-se que a aplicação da Realidade Virtual na Terapia Ocupacional vem crescendo e se consolidando nos últimos anos, mas que ainda existe a necessidade de ser estimulada no meio científico da área profissional específica, evidenciando essas práticas vivenciadas individualmente ou em equipes, através de publicaçôes científicas e relatos metodológicos das experiências exitosas.

Conhecer as particularidades do paciente, por meio de uma avaliação especializada, apresentou suma relevância no uso da RV como recurso terapêutico, visto ser primordial no levantamento de dados e evidências de atividades ou equipamentos mais adequados para cada paciente. De mesmo modo, a apropriação e a habilitação para o uso de equipamentos que utilizam a RV pelo terapeuta ocupacional podem facilitar o uso do recurso e maximizar possíveis benefícios, tornando a prática mais interativa e com maior envolvimento do cliente.

O uso da RV, enquanto prioridade singular ao processo terapêutico ocupacional, ainda necessita de pesquisas mais aprofundadas que comprovem sua efetividade e consistência. Desse modo, a RV náo substitui uma sessão de terapia convencional, mas deve ser usada como um complemento valioso ao processo terapêutico. Apesar de ser apontada como um recurso mais utilizado em jovens, a aplicabilidade da RV em idosos e crianças náo exclui os ganhos obtidos e deve ser incentivada.

Observou-se que a evolução tecnológica tem aproximado, aos poucos, o terapeuta ocupacional dos recursos informatizados em suas intervençóes convencionais, propiciando um crescimento do arsenal de recursos interativos que podem ser utilizados para intervir. Alguns equipamentos, a exemplo do Nintendo $W_{i i}{ }^{\circledR}$, possui um recurso interno que possibilita avaliar o indivíduo que o utiliza, dividindo-se em categorias, como: peso, altura, equilíbrio, movimentação, entre outras, que podem ser gravados e comparados ao final do plano de tratamento. Dessa forma, dá a possibilidade para o profissional avaliar e intervir usando o mesmo equipamento, de acordo com a necessidade de seu paciente.

Os estudos apresentados mostraram que, após as sessôes de RV, os indivíduos apresentaram ganhos motores, cognitivos e psicoafetivos, influenciando 
diretamente no desempenho ocupacional. Desse modo, podemos perceber a prática da RV como um viés aplicável e motivador para a maioria dos indivíduos analisados nos referentes estudos, possibilitando que equipamentos, que antes eram vistos como meio de inclusão digital e divertimento, hoje se conectam aos aspectos de promoção de saúde e prevenção de riscos, para diferentes tipos de tratamentos e faixas etárias.

Por fim, este estudo busca contribuir para o fortalecimento das práticas em RV pela Terapia Ocupacional e espera-se que as evidências científicas possam acrescentar ao conhecimento terapêutico ocupacional e de outras áreas de interesse, para futuras discussôes sobre as múltiplas possibilidades na difusão e atualização do uso da RV, na atualidade, para melhoria da saúde da população.

\section{Referências}

ADAMOVICH, S. V. et al. Sensorimotor training in virtual reality: a review. Neuro Rehabilitation, Philadelphia, v. 25, n. 1, p. 1-21, 2009. PMid:19713617.

ALBANI, G. et al. Common daily activities in the virtual environment: a preliminary study in parkinsonian patients. Neurological Sciences, New Orleans, v. 23, p. 49-50, 2002. Suplemento 2. http://dx.doi.org/10.1007/ s100720200064. PMid:12548338.

AMERICAN OCCUPATIONAL THERAPY ASSOCIATION - AOTA. Occupational Therapy Practice Framework: Domain \& Process. The American Journal of Occupational Therapy, Bethesda, v. 62, n. 6, p. 625-683, 2008. http://dx.doi.org/10.5014/ajot.62.6.625.

AMERICAN OCCUPATIONAL THERAPY ASSOCIATION - AOTA. Occupational Therapy Pratice Framework: Domain \& Process. The American Journal of Occupational Therapy, Bethesda, v. 68, p. 1-48, 2014. Suplemento 1.

BARBOSA, C. D. P. Análise da frequência cardíaca de adultos jovens saudáveis durante performance em um jogo de realidade virtual de imersão. 2013. $73 \mathrm{f}$. Dissertação (Mestrado em Terapia Ocupacional) - Universidade Federal de São Carlos, São Carlos, 2013.

BERSCH, R. Introdução à Tecnologia Assistiva. Porto Alegre: Assistiva, 2013. Disponível em: <http://www. assistiva.com.br/Introducao_Tecnologia_Assistiva.pdf>. Acesso em: $10 \mathrm{dez} .2014$.

BEZ, M. R. et al. Relato experiência: uso do SCALA em turma inclusiva. In: CONGRESSO BRASILEIRO DE COMUNICAÇÃO ALTERNATIVA, 5., 2013, Gramado. Anais... Gramado: Universidade Federal do Rio Grande do Sul, 2013. Disponível em: <http://www.ufrgs.br/teias/isaac/VCBCAA/pdf/116203_1.pdf>. Acesso em: 12 dez. 2014.

BRASIL. Ministério da Educação. Instituiçôes de Educação Superior e cursos cadastrados. Brasília, 2014. Disponí- vel em: <http://emec.mec.gov.br/>. Acesso em: $12 \mathrm{dez}$. 2014.

BUBLITZ, S. et al. Estresse em estudantes de enfermagem: uma revisão integrativa. Revista de Enfermagem da UFSM, Santa Maria, v. 2, n. 3, p. 530-538, 2012.

CALDAS, A. S. C.; FACUNDES, V. L. D.; SILVA, H. J. O uso da Medida Canadense de Desempenho Ocupacional em estudos brasileiros: uma revisão sistemática. Revista Terapia Ocupacional Universidade de São Paulo, São Paulo, v. 22, n. 3, p. 238-244, 2011.

CARVALHO, E. O. R. Eficácia da realidade virtual no tratamento de crianças com paralisia cerebral: revisão sistemática. 2013. 45 f. Monografia (Bacharelado em Terapia Ocupacional) - Universidade de Brasília, Brasília, 2013.

CONSELHO NACIONAL DE DESENVOLVIMENTO CIENTÍFICO E TECNOLÓGICO - CNPQ. Estatísticas e Indicadores da Pesquisa no Brasil. Parte II: regiōes demográficas. Brasília, 2006.

CORREA, A. G. D. Realidade aumentada musical para reabilitação: estudo de caso em musicoterapia. 2011.214 f. Tese (Doutorado em Ciências) - Escola Politécnica de São Paulo, São Paulo, 2011.

CORRÊA, C. G.; NUNES, F. L. S. Interaçấo com dispositivos convencionais e não convencionais utilizando integração entre linguagens de programação. In: NUNES F. L. S. et al. Abordagens práticas de realidade virtual e aumentada. In: SYMPOSIUM ON VIRTUAL AND AUGMENTED, 11., 2009, Porto Alegre. Anais... Porto Alegre: Sociedade Brasileira de Computação, 2009.

COSCRATO, G.; PINA, J. C.; MELLO, D. F. Utilização de atividades lúdicas na educação em saúde: uma revisáo integrativa da literatura. Acta Paulistana de Enfermagem, São Paulo, v. 23, n. 2, p. 257-263, 2010. http:// dx.doi.org/10.1590/S0103-21002010000200017.

COSTA, R. M. E. M.; CARVALHO, L. A. V. O uso de jogos digitais na Reabilitação Cognitiva. In: SIMPÓSIO BRASILEIRO DE INFORMÁTICA NA EDUCAÇÃO, 16., 2005, Juiz de Fora. Anais... Juiz de Fora, 2005. p. 19-21. Disponível em: <http://www.dominiopublico.gov.br/download/texto/la000001.pdf>. Acesso em: 09 dez. 2014.

CROSSETTI, M. G. O. et al. Revisão integrativa de pesquisa na enfermagem o rigor cientifico que lhe é exigido. Revista Gaúcha de Enfermagem, Porto Alegre, v. 33, n. 2, p. 8-9, 2012.

DE GRANDE, A. A. B.; GALVÃO, F. R. O.; GONDIM, L. C. A. Reabilitação virtual através do videogame: relato de caso no tratamento de um paciente com lesão alta dos nervos mediano e ulnar. Acta Fisiátrica, Natal, v. 18, n. 3, p. 157-162, 2011.

ERCOLE, F.; MELO, L. S.; ALCOFORADO, C. L. G. C. Revisão integrativa versus revisão sistemática. Revista Mineira de Enfermagem, Belo Horizonte, v. 18, n. 1, p. 9-11, 2014. 
FAVA, F. Jogando com o ar: o sopro como instrumento de acessibilidade nos jogos eletrônicos. In: SBGAMES, 7., 2008, Belo Horizonte. Anais... Belo Horizonte: SBGames, 2008. p. 115-121.

FEUERWERKER, L. C. M. Micropolitica e saúde: produção do cuidado, gestão e formação. Porto Alegre: Rede Unida, 2014.

FORTIN, I. Alice no país do espelho. O MUD: o jogo e a realidade virtual baseados em texto. Imaginario, Sáo Paulo, v. 12, n. 12, p. 171-194, 2006.

GARUZI, M. et al. Acolhimento na Estratégia Saúde da Família: revisão integrativa. Revista Panamericana de Salud Publica, Califórnia, v. 35, n. 2, p. 144-149, 2014.

INSTITUTO BRASILEIRO DE GEOGRAFIA E ESTATÍSTICA - IBGE. Política Nacional por Amostras à Domicilio (PNAD): acesso à internet e posse de telefone celular para uso pessoal. Rio de Janeiro, 2013. Disponível em: <http://www.ibge.gov.br/home/estatistica/ pesquisas/pesquisa_resultados.php?id_pesquisa $=40>$. Acesso em: 11 dez. 2014.

KIRNER, C. Evolução da Realidade Virtual no Brasil. In: SYMPOSIUM ON VIRTUAL AND AUGMENTED REALITY, 5., 2008, Porto Alegre. Anais... Porto Alegre: Sociedade Brasileira de Computação, 2008. p. 1-11.

LIMA, F. C.; MARINO, A. E. E.; PALHARES, M. S. Iniciação ao uso do computador: um relato de experiência com crianças com paralisia cerebral. Cadernos de Terapia Ocupacional da UFSCar, São Carlos, v. 14, n. 1, p. 33-42, 2006.

LOURENÇO, T. M. et al. Capacidade funcional no idoso longevo: uma revisão integrativa. Revista Gaúcha de Enfermagem, Porto Alegre, v. 33, n. 2, p. 176-185, 2012.

MATOS, V. S. B.; GOMES, F. S.; SASAKI, A. D. Aplicabilidade da reabilitação vestibular nas disfunçóes vestibulares agudas. Revista Equilibrio Corporal e Saúde, São Paulo, v. 2, n. 1, p. 76-83, 2010.

MATTOS, F. A. M.; SANTOS, B. D. D. R. Sociedade da informação e inclusão digital: uma análise crítica. Liinc em Revista, Rio de Janeiro, v. 5, n. 1, p. 117-132, 2009.

MENDES, I. S. et al. Realidade virtual: desenvolvimento e aplicabilidade no tratamento da dor secundária ao câncer de mama. In: SIMPÓSIO DE ENGENHARIA BIOMÉDICA DA UNIVERSIDADE FEDERAL DE UBERLÂNDIA, 6., 2013, Uberlândia. Anais... Uberlândia: Universidade Federal de Uberlândia, 2013.

MENDES, K. D. S.; SILVEIRA, R. C. C. P.; GALVÃO, C. M. Revisão integrativa: método de pesquisa para incorporação de evidencias na saúde e na enfermagem. Texto \& Contexto - Enfermagem, Florianópolis, v. 17, n. 4, p. 758-764, 2008.
MERHY, E. E. A perda da dimensáo cuidadora na produçáo da saúde: uma discussão do modelo assistencial e da intervenção no seu modo de trabalhar a assistência. In: MERHY, E. E. Sistema Único de Saúde em Belo Horizonte: reescrevendo o público. São Paulo: Xamã, 1998. p. 103-120.

MONTEIRO, C. B. M. Realidade virtual na paralisia cerebral. São Paulo: Plêiade, 2011.

MUNGUBA, M. C. S. Educação na saúde: sobreposição de saberes ou interface? Revista Brasileira de Promoção da Saúde, Fortaleza, v. 23, n. 4, p. 295-296, 2010. http://dx.doi.org/10.5020/18061230.2010.p295.

MUNGUBA, M. C. S. Terapia ocupacional em ação interdisciplinar: jogos educativo-nutricionais na prevenção da obesidade infantil. 2008. 128 f. Tese (Doutorado em Ciências da Saúde) - Universidade Federal do Rio Grande do Norte, Rio Grande do Norte, 2008.

MURAGAKI, C. S. et al. A utilização de jogos pela terapia ocupacional: contribuição para a reabilitação cognitiva. In: ENCONTRO LATINO AMERICANO DE INICIAÇÃO CIENTÍFICA, 10., 2006, São José dos Campos. Anais... São José dos Campos: Universidade do Vale do Paraíba, 2006.

NASCIMENTO, D. B.; CARVALHO, G. F. J.; COSTA, R. M. E. M. ReabRA: Reabilitação Cognitiva através de uma aplicaçáo de Realidade Aumentada. In: WORKSHOP DE REALIDADE VIRTUAL E AUMENTADA, 5., 2008, Rio de Janeiro. Anais... Rio de Janeiro: Universidade do Estado do Rio de Janeiro, 2008. Disponível em: <http://www2.fc.unesp.br/wrva/ artigos/50466.pdf>. Acesso em: 09 dez. 2014.

NETTO, A. V.; MACHADO, L. S.; OLIVEIRA, M. C. F. Realidade virtual: definiçóes, dispositivos e aplicaçôes. Tutorial. Revista Eletrônica de Iniciação Científica da $S B C$, Porto Alegre, v. 2, n. 2, p. 1-33, 2002.

NUNES, F. L. S. et al. Realidade Virtual para saúde no Brasil: conceitos, desafios e oportunidades. Revista Brasileira de Engenharia Biomédica, Rio de Janeiro, v. 27, n. 4, p. 243-258, 2011. http://dx.doi.org/10.4322/ rbeb.2011.020.

OLIVEIRA, L. et al. Evaluation of cognitive technologies in geriatric rehabilitation: a case study pilot project. Occupational Therapy International, Massachusetts, v. 17, n. 2, p. 53-63, 2010a. http://dx.doi.org/10.1002/ oti.290. PMid:20146197.

OLIVEIRA, P. R. et al. Estudo do uso de softwares e recursos de acesso ao computador para pacientes com Distrofia Muscular de Duchenne. Cadernos de Terapia Ocupacional da UFSCar, São Carlos, v. 18, n. 2, p. 139$148,2010 \mathrm{~b}$

OLIVEIRA, A. I. A.; SILVA, R. L. M.; ZAPAROLI, D. A. Inovação tecnológica \& inclusão social. Belém: EDUEPA, 2011.

OLIVEIRA, T. T.; MUNGUBA, M. Jogo eletrônico mediando a inclusão de pessoas com deficiência intelec- 
tual no mundo do trabalho. Revista de Iniciação Científca da FFC, Marília, v. 11, n. 2, p. 1-15, 2011.

PEREZ, C. R.; NEIVA, J. F. O.; MONTEIRO, C. B. M. A vivência da tarefa motora em ambiente virtual e real: estudo da devolução do saque do tênis de mesa. Pensar a Prática, Goiânia, v. 17, n. 1, p. 191-199, 2014.

PERRANI, L.; BRESSAN, R. T. Wii Will Rock You: Nintendo Wii e as relaçóes entre interatividade e corpo nos videogames. In: SIMPÓSIO BRASILEIRO DE JOGOS PARA COMPUTADOR E ENTRETENIMENTO DIGITAL, 6., 2007, São Leopoldo. Anais... São Leopoldo: Unisinos, 2007. Disponível em: <http:// www.petfacom.uff.br/wordpress/arquivos/artigos/Artigo_3_Wii.pdf>. Acesso em: 10 dez. 2014.

PROCHNOW, A. et al. Acidente de trabalho: uma revisão integrativa. Revista de Enfermagem da UFSM, Santa Maria, v. 2, n. 1, p. 156-164, 2012.

REIS, G. Videogame: história, gêneros e diálogo com o cinema. 2005. 190 f. Dissertação (Mestrado em Comunicação) - Universidade de Marília, Marília, 2005.

ROCHA, P. R.; DEFARAVI, A. H.; BRANDÁO, P. S. Estudo da viabilidade da utilização do Kinect como ferramenta no atendimento fisioterapêutico de pacientes neurológicos. In: SIMPÓSIO BRASILEIRO DE JOGOS E ENTRETENIMENTO DIGITAL, 11., 2012, Brasília. Anais... Brasília: SBGames, 2012.

ROSA, R. R.; BERRETIN-FELIX, G. Fala e reabilitação oral protética: revisão integrativa. Distúrbios da Comunicação, São Paulo, v. 27, n. 1, p. 174-181, 2015.

SANTOS FILHO, J. V. A. S. et al. Software para dispositivo eletrônico baseado em Comunicação Aumentativa Alternativa (CAA) para pessoas com deficiência. Revista de Iniciação Cientifica, Salvador, v. 12, n. 1, p. 1-15, 2012.

SILVA, M. L.; FRÈRE, A. F.; OLIVEIRA, H. A. D. Desenvolvimento de jogos de computador como atividade terapêutica no tratamento de dependentes químicos. In:
CONGRESSO BRASILEIRO DE INFORMÁTICA NA SAÚDE, 9., 2004, Ribeirão Preto. Anais... Ribeirão Preto: MedSolution, 2004.

SONY(C) Computer Enterteinement Inc. Move. Me User's Guide. Minato-Ku: SCEI, 2011. Disponível em: <http://uk.playstation.com/media/IO0_qmi1/moveme-userguide_0223.pdf>. Acesso em: 15 dez. 2014.

SOUZA, M. T.; SILVA, M. D.; CARVALHO, R. Revisão Integrativa: o que é e como fazer. Einstein, São Paulo, v. 8, n. 1, p. 102-106, 2010. http://dx.doi.org/10.1590/ S1679-45082010RW1134.

VIANNA, A. S. G.; MACHADO, L. S. Controle e gerenciamento de ambientes reais educacionais através de ambientes virtuais. In: INTERNATIONAL CONFERENCE ON ENGINEERING AND COMPUTER EDUCATION - ICECE, 6., 2009, João Pessoa. Anais... João Pessoa: COPEC, 2009. Disponível em: <http:// www.di.ufpb.br/liliane/publicacoes/2009_icece1.pdf>. Acesso em: 15 dez. 2014.

WATANABE, M. K. F; TSUKIMOTO, D. R.; TSUKIMOTO, G. R. Terapia ocupacional e o uso do computador como recurso terapêutico. Acta Fisiátrica, São Paulo, v. 10, n. 1, p. 17-20, 2003.

WHITTEMORE, R.; KNAFL, K. The integrative review: updated methodology. Journal Advenced Nursing, United Kingdom, v. 52, n. 2, p. 546-553, 2005. PMid:16268861

WORLD FEDERATION OF OCCUPATIONAL THERAPISTS - WFOT. Definition of occupational therapy. Western, 2012. Disponível em: <http://www.wfot. org/AboutUs/AboutOccupationalTherapy/DefinitionofOccupationalTherapy.aspx>. Acesso em: 16 ago. 2015.

ZIJLSTRA, W. P. et al. Outlier detection in the medical Questionnaire Rising and Sitting Down (QR \&S). In: SHIGEMASU, K. et al. (Org.). New trends in psychometrics. Tokyo: Universal Academy Press, 2008. p. 6056012.

\section{Contribuição dos Autores}

Tayane Leoncio Caiana foi responsável pela concepção, estruturação e organização do conteúdo da pesquisa. Dhyego de Lima foi responsável pela orientação da pesquisa, análise e revisáo dos dados apresentados no artigo. Ana Carollyne Dantas foi responsável pela coorientação em todas as fases da pesquisa e participação na redação e revisão do artigo final. Todos os autores aprovaram a versão final do texto. 